\title{
Estimation of Export Supply Function for Citrus Fruit in Pakistan
}

\author{
Usman Haleem, Khalid Mushtaq, Azhar AbBas, and A. D. Sheikh
}

\section{INTRODUCTION}

Nature has blessed Pakistan with an ideal climate for growing a wide range of delicious fruits. Thus a very wide range of tropical, sub-tropical and temperate fruits are grown in the country. Over the years, Pakistani experts have developed unique strains of exotic fruit varieties. Pakistan is producing a large variety of fruits on an area of 734.6 thousand hectares with a total production of 5712.4 thousand tons. Out of this 354.4 thousand tons fruit is exported from the country [Pakistan (2004)].

Horticulture is an important sub-sector of agriculture and plays a vital role not only in rejuvenation of rural economy but also in improving human nutrition which is often deficient in ingredients such as vitamins and minerals. Citrus and mango are the main fruit crops which contribute substantially to the national income.

Citrus is a prized fruit of Pakistan and holds number one position among all fruits both in area and production in the country. No doubt, it was originated in tropical areas around Southern Himalayas, South Eastern Asia and Indonesian Archipelago but it was spread throughout the world on both sides of equator making a citrus belt of 35 degree latitude in South Australia in Southern hemisphere. The quality of the citrus fruit varies in different regions. The areas with semi-tropical climate near the southern and northern most latitude limits are the best for commercial production [Mahmood and Akhtar (1996)].

Today, Pakistan stands among the top ten citrus growing countries in the world. Kinnow is grown primarily in the plains of Punjab province of Pakistan. It has good demand abroad, as foreign fruit vendors generally prefer Kinnow from Pakistan. Its production has increase overtime. The production of citrus was 671.1 thousand tones in 1975 and has increased to 1760.3 thousand tones in 2004 [Pakistan (2004)].

When viewed against experience of many successful developing countries, Pakistan's export performance has been lackluster [Khan (1998)]. Total exports grew at an average annual rate of 6 percent during 1990s. Exports however stagnated at

Usman Haleem and Khalid Mushtaq are based at the University of Agriculture, Faisalabad. Azhar Abbas and A. D. Sheikh are based at the Technology Transfer Institute, (PARC) AARI, Faisalabad. 
around US\$ 8 billion, during second half of 1990s. [Pakistan (2004)]. It was observed that the late 1970s and early 1980s were periods of considerable instability in world agricultural markets in which fluctuating world market prices, unstable currency exchange and interest rates led to major instability in export earnings of developing countries [Tambi (1999)].

The agriculture sector's dependence on nature causes fluctuations in supply conditions of primary products, thus making export receipts unstable. Also, primary products are known to have low supply and demand elasticities. Although the supply constraint rather than external demand constraint has been considered an important factor inhibiting the growth of agricultural exports of developing countries, much of the debate on these issues hinges on the adequacy of empirical evidence on the quantitative significance of various factors affecting supply and demand for agricultural exports. The export supply function indicates the relative influence of relevant price and non-price factors and associated policies in stimulating the supply of exports [Islam and Subramanian (1989)].

In case of Pakistan, the share of primary export earnings declined from 19 to 12 percent during 1990s. Earnings from primary exports rose in absolute value terms from Rs 25,820 million in $1990-91$ to Rs 52,214 million in 2003-04. Pakistan is exporting Kinnow to various countries and it holds first position, contributing about 30 percent of all the fruits being exported. Pakistan exported 18.2 thousand tones citrus in 1975 which increased to 149.587 thousand tones in 2004. Pakistani citrus has a great demand in Gulf States, Singapore, Malaysia, United Kingdom and Germany [Pakistan (2004)]. Being the traditional exporter of horticultural commodities like citrus and in the light of growing awareness about the importance of exports in the overall economic development of Pakistan, this study was designed to examine whether changes in fruit prices, the national product and foreign exchange rate have any effects on the volume of commodities exported like citrus from Pakistan. Reliable estimates of determinants of export earnings are essential for policy decisions. This study used co-integration technique to analyse Pakistan's export supply of citrus with following specific objectives:

- to examine the export performance of citrus fruit since 1975;

- to estimate empirically the export supply function for citrus fruit.

\section{THEORETICAL CONSIDERATION AND EMPIRICAL METHODOLOGY}

\section{Data and Model Specification}

The secondary data regarding domestic production, export quantity, export and domestic prices, GDP and exchange rate was utilised in this study. Annual time series data from 1975 to 2004 were analysed through the following model. 


$$
\ln Q E_{i t}=\alpha_{0}+\beta_{1} \ln E P_{i t}+\beta_{2} \ln P_{i t}+\beta_{3} \ln D P i t+\beta_{4} \ln E R_{t}+\beta_{5} \ln G D P_{t}+\mu_{i t}
$$

Where

$\ln Q E_{i t}=$ Quantity of citrus exported in thousands metric tones.

$\ln E P_{i t}=$ Export price measured by the export unit value index $(2000=100)$.

$\ln P_{i t}=$ Quantity of domestic production of citrus.

$\ln D P i t=$ Wholesale price index representing domestic price index $(2000=100)$

$\ln G D P_{t}=$ Pakistan's gross domestic product measured at constant factor cost of 2000.

$\ln E R_{t}=$ Exchange rate in terms of dollar.

$\mu_{i t}=$ Stochastic error term.

Standard supply theory suggests that the partial derivatives of supply of exports with respect to export and domestic prices of export goods are positive and negative, respectively. The domestic production $\left(P_{i t}\right)$ is expected to have a positive sign as higher production results in higher exportable surplus, ceteris paribus. On an a priori basis, a direct relationship is expected between quantity exported of a commodity $\left(Q E_{i t}\right)$ and Gross Domestic Product $\left(G D P_{t}\right)$, a reflection of robustness of the economy. The exchange rate plays a crucial role in explaining the variations in net exports of a commodity especially in a country where exchange rates are volatile. Higher exchange rates that occur during devaluation of domestic currency lead to increased exports. Thus a positive sign is anticipated between the exchange rate and exports.

\section{Analytical Technique}

Tabulation method was used to examine the export performance of Pakistan's agriculture over the last thirty years. Furthermore, the study used recently developed time series technique i.e. co-integration analysis, to estimate supply elasticity for citrus export from Pakistan. Recent developments in time series econometrics indicate that most time series are non-stationary. If the series is non-stationary then the use of the usual statistical tools to analyse data is not appropriate. Most economic time series are trended over time and regressions between trended series may produce significant results with high $R^{2}$ s, but may be spurious or meaningless [Granger and Newbold (1974)].

The concept of co-integration states that an individual series can wander extensively, but when paired with another series or a set of series, the pairs tend to move together over time and the difference between them are constant (i.e., stationary). A stationary series has a tendency to return to its mean value constantly and to fluctuate around it in a more or less constant range.

Consider the following first order autoregressive model:

$$
Y_{t}=\varphi Y_{t}-1+u_{t} \quad t=1, \ldots \ldots, T \quad \ldots \quad \ldots \quad \ldots .
$$


If $\varphi<1$, the series $Y_{t}$ is stationary and if $\varphi=1$, the series is non-stationary and is known as random walk. $Y_{t}$ in (1) can be made stationary after differencing once (although in general this is not necessarily the first-difference). The number of times a series needs to be differenced in order to achieve stationary depends upon the number of unit roots it contains. If a series becomes stationary after differencing $d$ times, then it contains $d$ unit roots and is said to be integrated of order $d$, denoted to $I(d)$. In (1) where $\varphi=1, Y_{\mathrm{t}}$ has a unit root and thus $Y t \sim I(1)$.

\section{Testing for Unit Roots}

Dickey-Fuller (DF) test [Dickey and Fuller $(1979,1981)]$ is most commonly used for testing unit root. The DF-test requires estimating the following by OLS:

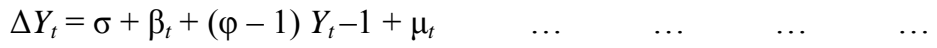

Equation (2) indicates that the series $Y_{t}$ has both stochastic and deterministic trends and can be used as a DF-equation for testing the unit root hypothesis i.e., Ho: $(\varphi-1)=0$. The test statistic used to test the unit root hypothesis is the Tt-statistic. If the calculated $T t$-value ( $t$-value of the coefficient $\varphi-1)$ is greater than the critical $T t$ value, then $Y t$ is non-stationary.

From (2) we can also test the joint hypothesis of unit root and no trend i., Ho: $(\varphi-1)=\beta=0$ against the alternative hypothesis of trend stationary i.e., H1: $(\varphi-1)$ $=\beta \neq 0$ by using the $\varphi$ - statistic with critical values from Dickey and Fuller (1981, Table (Vt, p. 1063). If the calculated ( $\varphi-1)$ value is less than the critical value, the null is rejected; Yt is stationary with a significant trend and is a trend stationary series.

If the error term is not white-noise, there is autocorrelation in the residuals. To overcome this problem first, we can generalise the testing Equation of (3.2) or second, we can adjust the DF-statistics [Thomas (1997), p. 407]. It is common to follow the former that is the augmented Dickey-Fuller (ADF) test. For this lagged values of the dependent variable are included on the right hand side of the DFEquation of (2) which becomes:

$$
\Delta Y_{t}=\sigma+\beta_{t}+(\phi-1) Y_{t}-1+\sum_{i=1}^{k} \theta 1 \Delta Y_{t}-1+\mu_{t} \quad \ldots \quad \ldots
$$

Langrange Multiplier (LM) test [Holden and Perman (1994), p. 62] is used to know the number of lagged values of the dependent variable. If there is more than one unit root, then first it is tested for a unit root in the levels of the series $Y t$. If the hypothesis of the presence of a unit root is not rejected, we test the first difference (i.e. $\Delta Y t$ ) for the presence of a second unit root and so on. This testing procedure from lower to higher orders of integration continues until the null of a unit root is rejected. 


\section{Co-integration with Multiple Equations: the Johansen Method}

Johansen's Full Information Maximum Likelihood (FIML) approach [Johansen (1988); Johansen and Juselius (1990)] was used to test for co-integration and it allows the estimation of all possible co-integrating relationship and develops a set of statistical tests about how many co-integrating vectors exist.

The Johansen maximum likelihood approach for multivariate co-integration is based on the following vector autoregressive (VAR) model:

$$
Z t=A t Z_{t}-1+\ldots+A k Z_{t}-k+\mu t \quad \ldots \quad \ldots \quad \ldots . \quad \ldots
$$

Where $Z_{t}$ is an $(n \times 1)$ vector of $I(1)$ variables, $A_{t}$ is an $(n \times n)$ matrix of parameters, $\mu_{t}$ is $(n \times 1)$ vector of white-noise errors. Since $Z_{t}$ is assumed to be non-stationary, it is convenient to rewrite (4) in its first-difference or error correction form as:

$$
\Delta Z_{t}=\Gamma_{1} \Delta Z_{t-1}+\ldots+\Gamma_{k-1} \Delta Z_{t-k+1}+\Pi Z_{t-k}+\mu_{t} \quad \ldots \quad \ldots
$$

Where $\Gamma_{i}=-\left(I-A_{1}-A_{2}-\ldots-A_{i}\right),(i=1, \ldots k-1)$, and $\Pi=-\left(I-A_{1}-A_{2}-\ldots .-A_{k}\right)$.

Equation (5) differs from the standard first-difference form of the VAR model only through the inclusion of term $\Pi Z_{t-k}$. This term provides information about the long-run equilibrium relationship between the variables in $Z_{t}$. If the rank of the $\Pi$ matrix, $r$, is $0<r<n$, there are ' $r$ ' linear combinations of the variables in $Z_{t}$ that are stationary. In this case, the $\Pi$ matrix can be decomposed into two matrices $\alpha$ and $\beta$ such that $\Pi=\alpha \beta$, where $\alpha$ is the error correction term and $\beta$ contains ' $r$ ' distinct cointegrating vectors i.e., the co-integrating relationships between the non-stationary variables. If there are variables which are $I(0)$ and are insignificant in the long-run co-integrating space but affect the short-run model, (5) can be rewritten as:

$$
\Delta Z_{t}=\Gamma_{1} \Delta Z_{t-1}+\Psi D_{t}+\mu_{t}
$$

Where $D_{t}$ represent the $I(0)$ variables, which are often included to take account of short-run shocks to the system such as policy interventions. Two likelihood ratio (LR) tests are constructed for detecting the presence of a single co-integrating vector. The first is the trace test statistics:

$$
\lambda_{\text {trace }}=-2 \ln Q=-T_{i} \sum_{=r+1}^{p} \ln \left(1-\lambda_{t}\right)
$$

It tests the null hypothesis of at most $r$ co-integrating vectors against the alternative that it is greater than $r$. The second is the maximal-eigenvalue test:

$$
\lambda_{\max }=-2 \ln (\mathrm{Q}: r \mid r+1)=-\operatorname{Tin}\left(1-\lambda_{r+1}\right)
$$

Which tests the null hypothesis of $r$ co-integrating vectors against the alternative that it is $r+1$. The critical values for these tests have been derived by Monte Cario simulations and tabulated by Johansen (1988). 
A number of issues need to be addressed before using this methodology. First, the endogenous variables included in the VAR are all $I(1)$. Second, the additional exogenous variable included in the VAR which explain the short-run behaviour need to be $I(0)$. Third, the choice of lag length $k$ (i.e., order) in the vector autoregressive (VAR) is important and the Akaike information criterions (AIC), Schwarz information criterion (SBC) are often used.

\section{RESULTS AND DISCUSSION}

\section{Export Performance of Citrus since 1975}

The export of citrus was 16000 metric ton in the year 1975 which grew gradually up to 1982 and reached to 40 thousand $\mathrm{mt}$, then after decreasing trend for some years its performance followed an oscillating trend upto 2004. The total export of citrus in 2004 was $113000 \mathrm{mt}$. The average export of citrus during the whole period stood at 44.82 thousand $\mathrm{mt}$ and average growth rate was 9.29 percent for this period.

Export of Citrus from 1975-2004

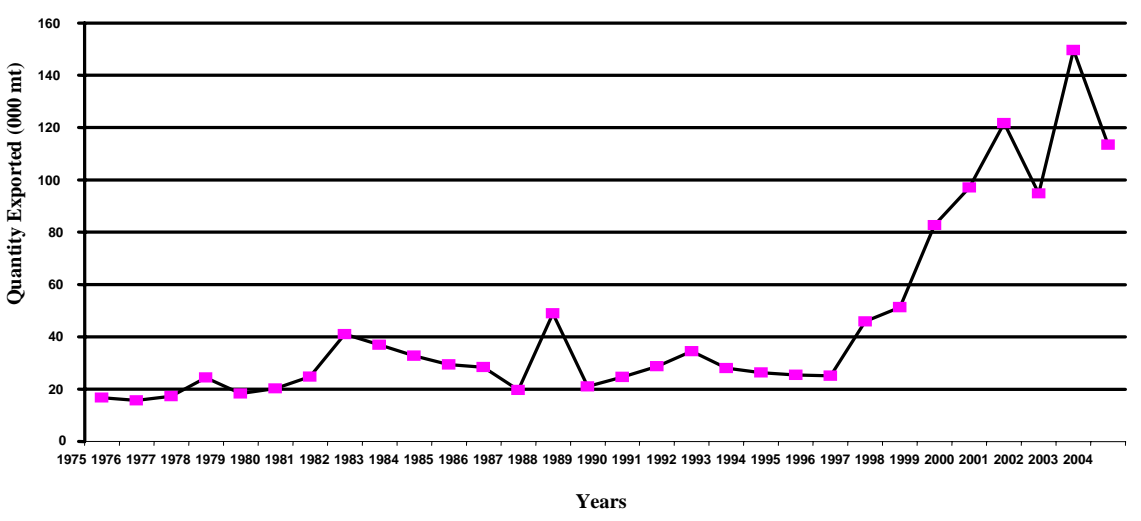

The graph shows that after 1983, citrus exports showed a very fluctuating performance crop failures, exchange rate etc. In 1982, Pakistani rupee was delinked from the dollar and a flexible exchange rate system was adopted. The strong dollar appreciated the Pakistani rupee vis-à-vis other currencies, reducing the competitiveness of Pakistan's exports in world markets [Zaidi (1999)].

After 1989, citrus export performance showed an upward trend, reaching to a value of 120 thousand $\mathrm{mt}$ in 2001. After showing a decline for one year, continuous increasing trend followed. After 1997, several export promotion strategies like duty drawback scheme, export finance schemes and export credit guarantee scheme etc. adopted by government helped in boosting exports. Recovery in export performance also started from 1997, as shown by an upward movement of the curve. 


\section{Unit Root Results (Test for Stationarity)}

The production of citrus (PC), the quantity of citrus exports (CE), export and domestic prices of citrus (EPC \& DPC), exchange rate (ER) and gross domestic product (GDP) of country were tested for unit roots for the period (1975-2004). Table 1 reports the results all the series (in log form) for unit roots using Augmented Dickey-Fuller (ADF) test both with and without a linear trend. Both models indicate that all the series are I (1), except PC (Production of Citrus) where stationarity is shown in the non-trended model and in EPC, stationarity is shown in the trended model. In non-trended model, the absolute values of the ADF statistics for all variables except PC are well below the 95 percent critical value (CV) of the test (2.99) and hence the null hypothesis that all the variables except PC have unit roots is firmly accepted to conclude that all the series are non-stationary except PC which is stationary series. In trended model, the absolute values of the ADF statistics for all variables except EPC are well below the 95 percent critical value of the test $(-3.60)$ and thus the series are non-stationary whereas the absolute value of the ADF statistics for EPC (4.56) is well above the 95 percent critical value of the test (-3.60) indicating that EPC is stationary series. These results direct us to move towards the more authenticated test called $\varnothing_{3}$ Test. The null hypothesis in $\varnothing_{3}$ Test is that the variable observed have unit root with no trend against the alternative that the variables are trend stationary. The values of test statistics for all the variables are below the 95 percent critical values of the test (7.24), therefore, we reject the alternative and accept the null hypothesis. Thus we prefer non-trended model and conclude that PC and EPC are also I (1). Thus we accept null hypothesis of presence of unit root for all series and conclude that all series are non-stationary and order of integration I (1) i.e., become stationary after first difference.

Table 1

Unit Root (ADF) Test Statistic ( $H_{o}: 1$ Unit Root)

\begin{tabular}{ccccc}
\hline Variables & $\begin{array}{c}\text { Test Statistics for } \\
\text { Non-trended Model }\end{array}$ & $\begin{array}{c}\text { Test Statistics for } \\
\text { Trended Model }\end{array}$ & Trend & $\emptyset_{3}$ \\
\hline EC & -0.29 & -2.13 & 2.16 & 3.04 \\
PC & -4.51 & -2.20 & 0.84 & 3.78 \\
DPC & -2.29 & -2.31 & 1.18 & 1.18 \\
EPC & 1.93 & -4.56 & 3.23 & 3.23 \\
ER & -1.18 & -0.87 & 2.56 & 3.32 \\
GDP & -0.20 & -3.05 & 3.35 & 5.74 \\
C.V & $-\mathbf{2 . 9 9}$ & $-\mathbf{3 . 6 0}$ & $\mathbf{2 . 8 5}$ & $\mathbf{7 . 2 4}$ \\
\hline
\end{tabular}


For further confirmation we tested all the series (in first difference form) for unit roots using ADF-test, both with and without the linear trend. The results are reported in Table 2. In both non-trended and trended Models, the 1st differenced absolute values of test statistics for all the six variables are well above the 95 percent critical value of the test to reject the null hypothesis concluding that they have become stationary after 1 st differencing. This shows that they are I (1).

Table 2

\begin{tabular}{lcc} 
& Unit Root Results for First Difference Form $\left(\mathrm{H}_{1}=0\right)$ \\
\hline Variables & $\begin{array}{r}\text { Test Statistics for } \\
\text { Non-trended Model }\end{array}$ & $\begin{array}{c}\text { Test Statistics for } \\
\text { Trended Model }\end{array}$ \\
\hline DEC & -7.43 & -7.37 \\
DPC & -4.02 & -5.83 \\
DDPC & -7.53 & -7.36 \\
DEPC & -5.88 & -6.30 \\
DER & -4.01 & -4.07 \\
DGDP & -4.33 & -5.93 \\
C.V & $-\mathbf{2 . 9 7}$ & $-\mathbf{3 . 6 0}$ \\
\hline
\end{tabular}

\section{Co-integration Results}

Johansen approach was used to test for co-integration which provides likelihood ratio tests for the presence and number of co-integrating vectors among the series and produces long-run elasticities. This approach provided a means to analyse the number of co-integrating vectors in multivariate case thus leading to the estimation of export supply function for citrus.

\section{Export Supply Function for Citrus}

Quantity of Citrus Exported (CE) was assumed to be a function of citrus production (CP), domestic price index (DPC), export unit value index (EPC), exchange rate (ER), and Gross Domestic Product (GDP) of the country i.e.

$C E=f(C P, D P C, E P C, E R, G D P)$

In the first step, in estimation of citrus export supply function by Johansen's procedure, the adjusted LR-test, AIC and SBC were used for the selection of order of $\mathrm{VAR}$ and the results are reported in Table 3. 
Table 3

Selecting the Order of VAR for Citrus Export Model List of Variables Included in Unrestricted VAR

\begin{tabular}{|c|c|c|c|c|c|}
\hline \multicolumn{6}{|c|}{ List of Variables Included in Unrestricted VAR } \\
\hline$\overline{\mathrm{LCE}}$ & LCP & LDPC & LEPC & LER & $\overline{\mathrm{LGDP}}$ \\
\hline
\end{tabular}
List of Deterministic and /or Exogenous Variables

\begin{tabular}{cccc}
\multicolumn{3}{c}{ Constant } \\
\hline Order & AIC* & SBC* & Adjusted LR-Test \\
3 & 194.2290 & 120.3663 & \\
2 & 148.5142 & 97.9765 & $48.4236(0.081)$ \\
1 & 150.3682 & 123.1556 & $68.6583(0.590)$ \\
0 & 47.8562 & 43.9687 & $150.7395(0.004)$ \\
\hline
\end{tabular}

P-values in parentheses.

*AIC $=$ Akaike Information Criterion. $\mathrm{SBC}=$ Scharwz Bayesion Criterion.

The results indicate that the LR-test statistics rejects order zero, but does not reject the VAR with order one. However, Scharwz Bayesian Criterion and Akaike Information Criterion select order one and three respectively. Since we have short time series (30 observations) and to avoid over-parameterisation, we choose one as the order of VAR for our citrus export model.

The second step in Johansen procedure was to test for the presence and number of co-integrating vectors. The co-integrating results are presented in Table 4 .

Table 4

Co-integration Results for the Citrus Export Model

\begin{tabular}{lcccc}
\hline \multirow{2}{*}{ Equations Tested } & \multicolumn{4}{c}{ Maximal Eigenvalue Test } \\
\cline { 2 - 5 } & Null & Alternative & Statistic & $95 \%$ Critical Value \\
\hline LCE, LCP, & 1 & 1 & 57.9463 & 40.5300 \\
LDPC, LEPC, & 2 & 2 & 40.4878 & 34.4000 \\
LER, LGDP & 3 & 3 & 24.4102 & 28.2700 \\
& 4 & 4 & 19.9634 & 22.0400 \\
& 5 & 5 & 12.2348 & 15.8700 \\
& & 6 & 8.7452 & 9.1600 \\
LCE, LCP, & 0 & 1 & 163.7877 & 102.5600 \\
LDCM, LEPC, & 2 & 2 & 105.8414 & 75.9800 \\
LER, LGDP & 3 & 3 & 65.3537 & 53.4800 \\
& 4 & 4 & 40.9435 & 34.8700 \\
& 5 & 5 & 20.9800 & 20.1800 \\
& & 6 & 8.7452 & 9.1600 \\
\hline
\end{tabular}


By employing the maximum eigenvalue statistic, it is found that the first time the null is not rejected when $r=2$. However it rejected the alternative hypothesis that there are three co-integrating vectors. Similarly the trace statistic did not reject the null hypothesis for the first time when $r=5$. This test suggested that there are five cointegrating vectors.

The Johansen's normalised estimates are presented in Table 5. The coefficients represent estimates of long-run elasticities of citrus export with respect to export price, domestic production, domestic price, exchange rate and GDP of country.

Table 5

Johansen Normalised Estimates for the Citrus Export Model

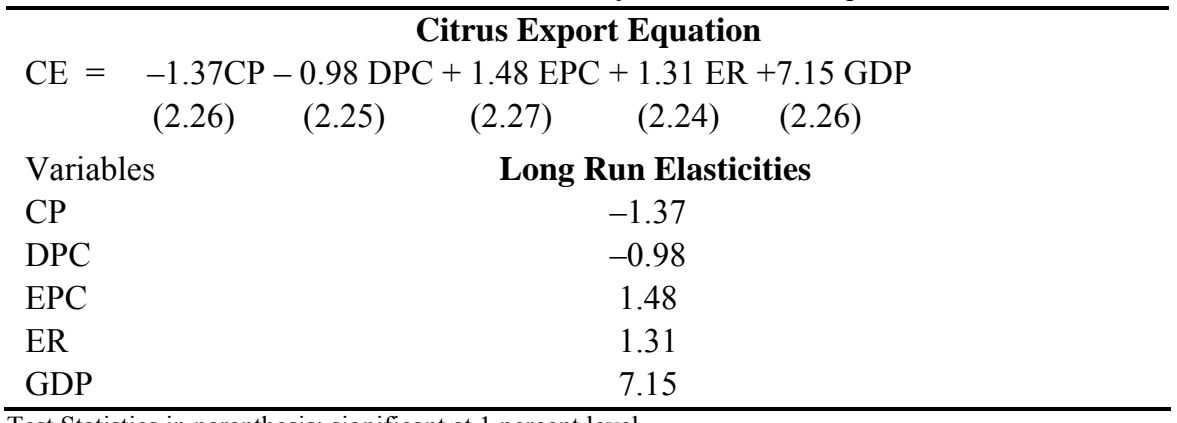

Test Statistics in parenthesis; significant at 1 percent level.

All the variables carried correct expected signs except $\mathrm{CP}$, which has a negative sign. In parenthesis are $t$-ratios, which when compared with the Table values at 1 percent significant level, showed that all the estimates are statistically significant. The elasticity for domestic production (CP) of citrus was -1.37 , though significant but has not the correct sign. This is understandable in the light of highly fluctuating domestic production of citrus and heavy dependence of our citrus exports on the domestic production. Domestic price of citrus (DPC) elasticity remained 0.98 showing a negative impact of 0.98 percent on citrus export quantity with one percent rise in domestic prices of citrus. The long-run elasticity for export price (EPC) was 1.48 meaning one percent rise in export price caused 1.48 percent increase in citrus export quantity. Thus the international price (export price) seemed to have a stronger impact on commercial crop exports. Earlier studies by Reddy and Narrayan (1992) confirmed the results. Exchange rate elasticity was found to be 1.31, which showed a very strong impact of currency devaluation over last thirty years on citrus exports. This exchange rate impact was the second international factor beside the export price, to affect greatly citrus export quantity. Devaluation makes the exports cheaper increasing the country's competitiveness in world markets. 
The long-run elasticity for Gross Domestic Product (GDP) was found to be 7.15 in our citrus export model. Thus one percent rise in GDP caused a 7.15 percent increase in the quantity of citrus exports. The stronger impact of GDP shows the importance of citrus crop in the economy of Pakistan. With the increase in robustness of economy, there is more emphasis on citrus exports to earn more foreign exchange through various incentives.

\section{CONCLUSION}

Importance of exports in the development of an economy cannot be denied. This is particularly true in case of a developing economy like Pakistan. Export of fruits is mainly concentrated in citrus and mango. The commodity concentration and the supply side fluctuations in fruit exports are known to have serious consequences for overall export earnings. It was in this context that the present study made its contribution by reviewing the performance of citrus fruit exports during last thirty years (1975-2004) and estimating the export supply function for citrus. Johansen's co-integration technique was followed in the estimation process.

The analysis brings out clearly that the share of fruit export has been declining over the years. Percentage share of fruit exports were 133.73 thousand tons during the period of thirty years. There were very less earnings from export of fruits in the early years which gradually increased at the end. The fluctuating performance of fruit exports is attributed to highly fluctuating domestic production, inconsistent export policies, currency devaluation, export duties, competitiveness of exports and situation in the international markets. Estimated results showed the importance of price and non-price factors in explaining export supply function for citrus.

In case of price factors, export price (international price) seemed to play important role in citrus export. The estimated exports price elasticity was 1.48 while domestic price elasticity was -0.98 . Considering non-price factors, the estimated elasticity for domestic production of citrus was -1.37 . The exchange rate seemed to be important in explaining variations in citrus exports. This was found to be a strong argument in the face of successive currency devaluation during past. Exchange rate elasticity was 1.31. Gross Domestic Product (GDP) of country seemed to have a positive association for citrus exports. The long run elasticity for this variable was 7.15. The overall results thus suggested that internal factors like domestic production, domestic prices play more important role than external factors in explaining variations in case of citrus export.

\section{REFERENCES}

Dickey, D. A., and W. A. Fuller (1979) Distribution of the Estimators for Autoregressive Time Series with a Unit Root. Journal of the American Statistical Association 74, 427-431. 
Dickey, D. A., and W. A. Fuller (1981) Likelihood Ratio Statistics for Autoregressive Time Series with a Unit Root. Econometrica 49, 1057-1072.

Granger, C. W. J., and P. Newbold (1974) Spurious Regressions in Econometrics. Journal of Econometrics 2, 111-120.

Holden, D., and R. Perman (1994) Unit Roots and Cointegration for the Economist. In B. B. Rao, Cointegration for the Applied Economists. New York: St. Martin's Press. p. 62.

Islam, N., and A. Subramanian (1989) Agricultural Exports of Developing Countries: Estimates of Income and Price Elasticities of Demand and Supply. Journal of Agricultural Economics 40:2, 221-231.

Johansen, S. (1988) Statistical Analysis of Cointegrating Vectors. Journal of Economic Dynamics and Control 12, 231-254.

Johansen, S., and K. Juselius (1990) Maximum Likelihood Estimation and Inference on Cointegration with Application to the Demand for Money. Oxford Bulletin of Economics and Statistics 52, 170-209.

Khan, A. H. (1998) The Experience of Trade Liberalisation in Pakistan. The Pakistan Development Review 37:4, 661-685.

Mahmood, A., and N. Akhtar (1996) The Export Growth of Pakistan: A Decomposition Analysis. The Pakistan Development Review 35:4, 693-702.

Pakistan, Government of (1975-2004) (Various Issues) Statistical Year Books. Islamabad: Federal Bureau of Statistics Ministry of Food, Agriculture and Livestock.

Pakistan, Government of (2004) Economic Survey. Islamabad: Finance Division, Economic Adviser's Wing.

Reddy, V. R., and K. B. Narrayan (1992) Trade Experience of Indian Agricultrue: Behaviour of Net Export Supply Functions for Dominant Commodities. Indian Journal of Agricultural Economics 47:1, 48-61.

Tambi, N. E. (1999) Co-integration and Error-Correction Modeling of Agricultural Export Supply in Cameroon. Agricultural Economics 20, 57-67.

Thomas, R. L. (1997) Modern Econometrics: An Introduction. Addison: Wesley Longman Limited.

Zaidi, S. A. (1999) Issues in Pakistan Economy. London: Oxford University Press. 159-180. 


\section{Comments}

The authors have taken up a burning issue as government of Pakistan is interested in expanding her export band of agricultural products beyond the conventional rice and cotton based export system. Such information would certainly serve as baseline information for the policy-makers for awarding necessary incentives or making changes in the existing policies. In this way, the authors have made significant contribution to the existing literature on trade analysis.

Export of horticultural products has great scope. At present, fruits worth 5.9 billion rupees are exported from Pakistan while the total export of agricultural products constitutes 709 billion rupees. In this way, the earnings from the export of fruits represent hardly one percent of total agricultural exports [Pakistan (2004)]. Citrus is the major fruit of Pakistan both in terms of area and production. The rapid expansion in its export is a recent phenomenon. At present more than 80 kinnow processing factories are working in the Sargodha district of Punjab and many of them are also directly involved in its export. Despite that more than 90 percent of the total citrus production is domestically marketed.

The authors deserve compliments over a rigorous analysis conducted. The period taken into consideration is quite short leaving little space for incorporating more number of variables into the analysis, which has been rightly mentioned in the paper. However, I have some comments on some of the variables used in the citrus export supply function. These are: (1) the wholesale and export price indices were used instead of using the actual data without explaining its logic or reference from past studies. Alternatively, it would be better to convert the nominal domestic wholesale prices into real wholesale prices by using consumer price index while export price may be converted into US\$/ton using the exchange rate. This would help making exchange rate redundant in the analysis. (2) As rapid expansion in citrus export is a recent phenomenon, therefore, in the major part of the period under consideration, the citrus wholesale prices presented a good reflection of production level in the country. Moreover, the level of prevailing price of a commodity in the domestic wholesale market also serves as incentive/disincentive for its export. Hence, the variable on wholesale price was a sufficient to be used. Alternatively, the difference in the wholesale and export prices may be used as indicator of incentive for increasing citrus export. (3) No doubt, national GDP reflects the strength of the economy, but changes in national GDP also reflects changes in per capita income. Therefore, a rise in per capita income induces changes in food consumption patterns. 
The literature on the analysis of household consumption patterns in Pakistan shows that the income elasticity of fruits consumption is greater than unit [e.g. Farooq and Ali (2002)], which means an overtime increase in per capita income should induce more consumption of citrus rather than export. This implies that the magnitude of the elasticity of export w.r.t. per capita income or GDP should be small in magnitude. On the other hand, given a very small share of fruits or horticultural crops in agricultural GDP as well as total volume and value agricultural exports, a one percent rise in GDP cannot influence the citrus export by more than 7 times. Therefore, a small sized positive coefficient rather negative sign of coefficient and its elasticity may be the a priori expectation. Hence, keeping in view the extreme importance and sensitivity of the issue under investigation, I would suggest looking into the results more thoroughly before drawing any conclusion and suggesting policy recommendations.

I shall also take this opportunity to make some corrections in the introduction section. (i) Referring to last two sentences in the first paragraph on page 2, the current statistics about total area, production and export of fruits in Pakistan are 734.6 thousand hectares, 5712.4 thousand tons and 354.4 thousand tons, respectively. (ii) Referring to second paragraph on page 2, kindly indicate reference for the statement on "horticultural crops contribute about 6 percent of the country's GDP and 20 percent of national food production". The sentence following this statement is a repetition of the last sentence in first paragraph on page 2. (iii) Referring to the last sentence on page 3 , the latest estimates of citrus production are 1760.3 thousand tons in 2003-04 rather than 1653.7 thousand tons. (iv) Referring to the second paragraph on page 3 , the reference quoted is not presented in the references section. (v) Referring to first paragraph on page 4, the estimates about the value of export of primary agricultural products are 9602.5 million rupees rather than Rs 52124 million. Similarly, the quantity of citrus exported in 1975 needs correction as in total 64.2 thousand tons of fresh and dry fruits were exported during 1975-76 and total export of citrus during 2003-04 was 149.587 thousand tons.

Finally, I think if the above-proposed comments are incorporated, the paper will provide a sound foundation to the policy-makers and development practitioners for promoting the export of this abundantly produced fruit from Pakistan.

Social Sciences Institute,

Umar Farooq NARC, Islamabad. 